AUSTRALIAN JOURNAL OF BASIC AND APPLIED SCIENCES

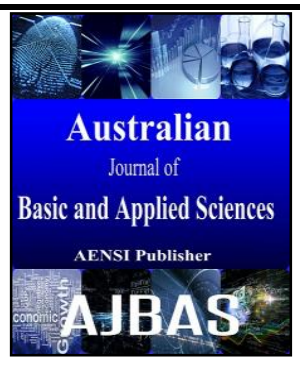

\title{
The Effect of Internal Context Factors on Individual Readiness to Change among the Non-academic Staff at the University of Malaya
}

\author{
${ }^{1}$ Wan Farahana, ${ }^{2}$ Sara Ghaffari, ${ }^{1}$ Dr. Mohammad Nazri, ${ }^{3}$ Dr. Jati Kasuma \\ ${ }^{1}$ Wan Farahana, Faculty of Business and Accountancy, University of Malaya, Kuala Lumpur, Kuala Lumpur, Malaysia \\ ${ }^{I}$ Sara Ghaffari, PhD Candidate in Faculty of Management, Universiti Teknologi Malaysia, Skudai, Johor, Malaysia. \\ ${ }^{q}$ Mohammad Nazri, Senior Lecturer, Faculty of Business and Accountancy, University of Malaya, Kuala Lumpur, Kuala Lumpur, Malaysia. \\ ${ }^{3}$ Jati Kasuma, Senior Lecturer, Faculty of Bunnies Management, Universiti Teknologi Mara, Sarawak, Malaysia.
}

\section{Address For Correspondence:}

Sara Ghaffari, PhD Candidate in Faculty of Management. Universiti Teknologi Malaysia, 81310, Skudai, Johor, Malaysia.

Phone: 00601112138170 ; E-mail: saragh7@yahoo.com

\section{ARTICLE INFO}

\section{Article history:}

Received 12 October 2017

Accepted 22 November 2017

Available online 6 December 2017

Keywords:

internal context factors, perceived organizational support, cohesion, trust in top management, communication climate, perceived supervisor support

\begin{abstract}
A B S T R A C T
Background: This study explores the effect of internal context factors on individual readiness to change among the non-academic staff at the University of Malaya. Five internal context factors were chosen based on the change readiness framework suggested by previous researchers. These variables are perceived organizational support, cohesion, trust in top management, communication climate, and perceived supervisor support. Objectives: The aim of this study is to examine the effect of internal context factors on individual readiness to change among the non-academic staff. The current study has three objectives. The first objective is to examine the effect of internal context factors on individual readiness to change (IRTC) among the nonacademic staff at University of Malaya. The second objective is to investigate the effect of each internal context factor on individual readiness to change (IRTC) among the non-academic staff at University of Malaya. The third objective of the study is to identify which variable in the model of internal context factors can be best predictor for the individual readiness to change. In this quantitative research, the descriptive statistics and inferential statistics were used for analyzing the data. The data collected was statistically analysed by using the Statistical Package for the Social Sciences (SPSS) version 23. The population of the research was 1140 employees. A total of 330 (82.5) respondents returned the questionnaires. Results: The study found that the internal context factors (measured as a single dimension) significantly and positively affectes the individual readiness to change (IRTC). The results indicate in positive conditions and supportive environment, the level of the individual readiness to change (IRTC) increases. The perceived supervisor support showed significant positive effect on the individual readiness to change (IRTC). The findings of this study indicate the best predictor for the individual readiness to change (IRTC) is perceived supervisor support (PSS). Conclusion: To know what factors may affect the individual readiness to change among the employees is important for the organizations. The result of the current research is helpful for the leaders of the University of Malaya to find out the importance role of their supervisory in increasing the level of individual readiness to change among the employees. As the current research only focused on the internal context factors and only some of these inertial variables were selected to study, there are other factors that may affect the individual readiness to change among the University employees which can be concerned by the future researchers.
\end{abstract}

Open Access Journal

Published BY AENSI Publication

(C) 2017 AENSI Publisher All rights reserved

This work is licensed under the Creative Commons Attribution International License (CC BY).

http://creativecommons.org/licenses/by/4.0/

\section{(c) (D) Open Access}

To Cite This Article: Wan Farahana, Sara Ghaffari, Dr. Mohammad Nazri., Dr. Jati Kasum, The Effect of Internal Context Factors on Individual Readiness to Change among the Non-academic Staff at the University of Malaya. Aust. J. Basic \& Appl. Sci., 11(14): 58-68 2017 


\section{INTRODUCTION}

To meet the needs of economy and society in Malaysia, the educational policies have been transformed in different phases. Higher Education Institutions (HEIs), particularly the public universities in Malaysia have expanded and developed tremendously to fulfil government's aspiration (Soaib and Sufean, 2012).

The most recent challenge that the Higher Education Institutions (HEIs) is facing is the decline in funding from the government. For many years, Higher Education Institutions (HEIs), particularly public universities depend greatly on government funding to finance their operational activities. $90 \%$ of funding in public universities is provided by the government and only 10\% come from students' fees (Ministry of Higher Education (MOHE), 2007a; 2007b). However, government has come out with the new plan in the National Higher Education Strategic Plan (NHESP) 2020 and National Higher Education Action Plan (NHEAP) 20072010 aimed to introduce new funding policy to public universities. Based on National Higher Education Strategic Plan (NHESP) 2020, public universities are required to subsidise their income using internal resources. For example, Research Universities were needed to subsidise $20 \%$ of their operating expenditures through internal resources during phase one (2007-2010). The percentage is targeted to increase with $25 \%$ from operating expenditure and 5\% from the development expenditure in phase two (2011-2015). Research Universities are expected to supplement $30 \%$ of their operating expenditure and $10 \%$ of the development expenditure during phase three (2016- 2020) (Abd Rahman and Alan, 2013).

University of Malaya is one of the public universities that had the most severe cut from the ministry's new funding policy. The top management of the university is facing a big challenge to keep the University at its best level and to achieve its goal to become 100 top ranked University in QS World University Ranking in the middle of financial restraint that worsen by the budget cut. The quality of teaching and learning, research and innovation are still needed to be maintained even though the University of Malaya is facing tough financial constraint. Therefore the leaders of the University of Malaya need to be creative and innovative in generating the University's income or to diversify the source of finance and at the same time to think of ways to manage internal operation costs more efficiently. Any effort which the University is planning to take to manage costs effectively will directly affect University' members particularly non-academic staff who work at the managerial and operational level.

\section{Literature Review:}

Daft (1982) defined organizational change as "the adoption of new behaviour or idea, occurring over a period of time". The early studies about change readiness began along with the research on organizational change (as cited in Walinga, 2008). Based on Kurt Lewin's change theory, a change would be implemented among the employees through three stages namely unfreezing, moving and refreezing. Armenakis et al. (1993) suggested a model for readiness creation which has been used widely by other researchers to expand the study of the change readiness concept. Armenakis et al. (1993) suggested that readiness for change is similar with the first stage proposed by Kurt Lewin's theory, which means that before attempting to introduce changes, leaders should make an initiative to assess the state of readiness among those who would be involved with the change process. Despite the widely research that have been done in change readiness especially on theories, models and development of measurement instruments, still implementation gap related with the transition from preparation stage to actual performance stage needs to study further (Thompson and Hunt,1996). Thus, more research should be done about this matter.

\section{Change Readiness Framework:}

Holt et al. (2007) had proposed a theoretical framework of change readiness. They define readiness for change as a comprehensive attitude that is influenced by the content simultaneously (what is being changed), process (how the change is being implemented), context (circumstances under which the change is occurring) and individuals' characteristics (characteristics of those being asked to change). In this framework, they propose that change readiness is a multidimensional construct consists of content, context, process and individuals' attributes.

\section{Individual Readiness to Change:}

Effective change initiatives shall begin at the individual level of analysis (Judge et al., 1999). George and Jones (2001) suggested that process of change should be analysed at the individual level due to the fact that individual readiness to change is the critical success factor in the organization in which individuals are the one that are going to implement the change. To analyse how individuals can accept and support the change effort successfully, organization needs to explore the change process at the individual level. The respond to change varies due to the differences of the individuals such as personality traits, coping styles, motivational needs and other factors (Judge et al., 1999). 
Armenakis and Bedeian (1999), denotes context to the "forces and conditions in the organization's internal and external environment influencing the organization's ability to be effective". This study only focuses on internal context which is also known as climate of change (Bouckenooghe et al., 2009) or organizational culture (Holt et al., 2007).

\section{Internal Context Factors:}

Internal context factors are the contextual variables that influence employees' perceptions and experiences of the internal circumstances and environment of change (Bouckenooghe, 2008; Bouckenooghe et al., 2009). Bouckenooghe suggests that internal context is one of the manageable approaches that organization can utilize to influence its members to accept change.

Studies have identified many contextual variables that affect the individual readiness to change. For example, Bouckenooghe et al. (2009) explored the internal context factors which are positively related with individual readiness to change such as politicking, participatory management, general support by supervision, trust in leadership and cohesion. Based on the change readiness framework by Holt et al. (2007) context is one of the dimensions that influences change readiness. Context is defined as the "attributes of environment where change initiative is implemented" and it comprises the environment and conditions within which the change occurs and the employees function".

\section{Perceived Organizational Support:}

In the context of change, the goal is to ensure the success of the change initiative. Perceived support from the organization can generate the employees' commitment to organization. In the context of change, perceived organizational support is a predictor for individual readiness to change (Eisenberger et al., 2002).

\section{Perceived Supervisor Support:}

The impact of supervisor support on the employees' performance and organizational commitment is discussed widely in organizational support literature and leader-member exchange (LMX) theory. However, not many studies have been done to study how supervisor and peer relations link with individual readiness to change (Naimatullah Shah, 2010). Employees who perceive they are being supported by their supervisors would normally show better performance and high organizational commitment (Eisenberger et al., 2002). The relationship between supervisor and employees is examined to understand the employees' feelings and thoughts (Chang, 1999). Chang found positive and significant results on employees' perception of supervisory support and career commitment. The study of this relationship is important in order to analyse how individuals would develop positive attitudes and behaviours through their supervisors. Naimatullah Shah (2010) proved that positive relationships between the supervisors and employees would result in openness and readiness to change.

\section{Cohesion:}

Cohesion among the work group is one type of social support that the employee would experience. Social support refers to the availability of another individual for information, affection, comfort, encouragement and reassurance (Warnberg and Banas, 2000). Strong cohesion increases readiness for change since it minimizes the stress and reduces anxieties about the new task or the responsibility the team would be facing with. Employees, who feel can receive support from their team especially from the high performance team, would have the capacity to navigate change. Mutual trust among the team members would help to reduce resistance and increase commitment to change (Fiorelli and Margolis, 1993). Bouckenooghe et al. (2009) suggest that cohesion has an influence on individual readiness to change.

\section{Trust in Top Management:}

Trust in top management refers to "the extent to which employees believe the top management wants to help the employees" (Mayer and Davis, 1999). Any movement taken by top management cannot be perceived as having personal gain but should be seemed as genuinely for the positive interest of the organizational members (Mayer et al, 1995). Employees, who have trust in their top management, will be more willing to accept and support any change effort by the organization (Wanberg and Banas, 2000).

\section{Communication Climate:}

Communication climate refers to the extent to which employees believe that they receive complete and legitimate information from the organization. Synder and Morris (1984) indicated that communication climate is a major predictor for organization success. Effective communication about the organizational policies and procedures which is accurate, open and adequate will lead to better job performance. Miller et al. (1994) stated that employees who receive adequate information are more willing to support changes. Holt et al. (2007) identified the communication climate as one of the variables that predicts individual readiness to change. 


\section{Significance of the Study:}

Understanding the internal context factors that may influence the individual readiness to change (IRTC) is an important issue which must be notably considered by the university leaders. The findings of the current research is important for the University leaders to identify which internal context factor is the best predictor for the individual readiness to change (IRTC) and focusing on their supervisor's role to increase the individual readiness to change (IRTC) among the non-academic employees.

\section{Research Objectives:}

The purpose of this study is to examine the internal context factors that may affect the individual readiness to change (IRTC) among the non-academic staff in the University of Malaya (UM).

This study is carried out:

1. To verify the effect of internal context factors on individual readiness to change (IRTC) among the non-academic staff at University of Malaya (UM).

2. To investigate the effect of each internal context factor on individual readiness to change (IRTC) among the non-academic staff at University of Malaya (UM).

3. To identify the variable in the model of internal context factors which can best predict individual readiness to change (IRTC).

\section{Theoretical Framework:}

The current study is based on the change readiness framework suggested by Holt et al. (2007). Internal context factors are defined as the dimensions that have influence on individual readiness to change. Therefore this study is conducted to investigate the relationship between internal context factors and individual readiness to change. Readiness to change is influenced by the support received from the internal environment such as organizational structure, climate and culture (Dalton and Gottlieb, 2003; Holt et al, 2007; Fariza et al., 2011). The support-based coping framework proposed by Miles et al. (2014) indicated (delete) indicates (add) that the internal context elements such as organization, supervisors and colleagues are the sources of support that can increase employees' commitment during organizational change. Based on that, the internal context variables namely perceived organizational support, perceived supervisor support and cohesion are chosen as variables for the current research. The researchers examine whether the perceived support from the internal environment particularly from these three variables would affect the individual readiness to change. The researchers also includ two other variables in this study namely trust in top management and communication climate. Holt (2002), Bouckenooghe et al. (2009) and Vakola (2014) indicate trust in top management as one of the contextual variables. Communication climate is one of the variables which is measured for internal context by Holt (2002), Holt et al. (2007) and Vakola (2014). Figure 1 shows the framework of this study.

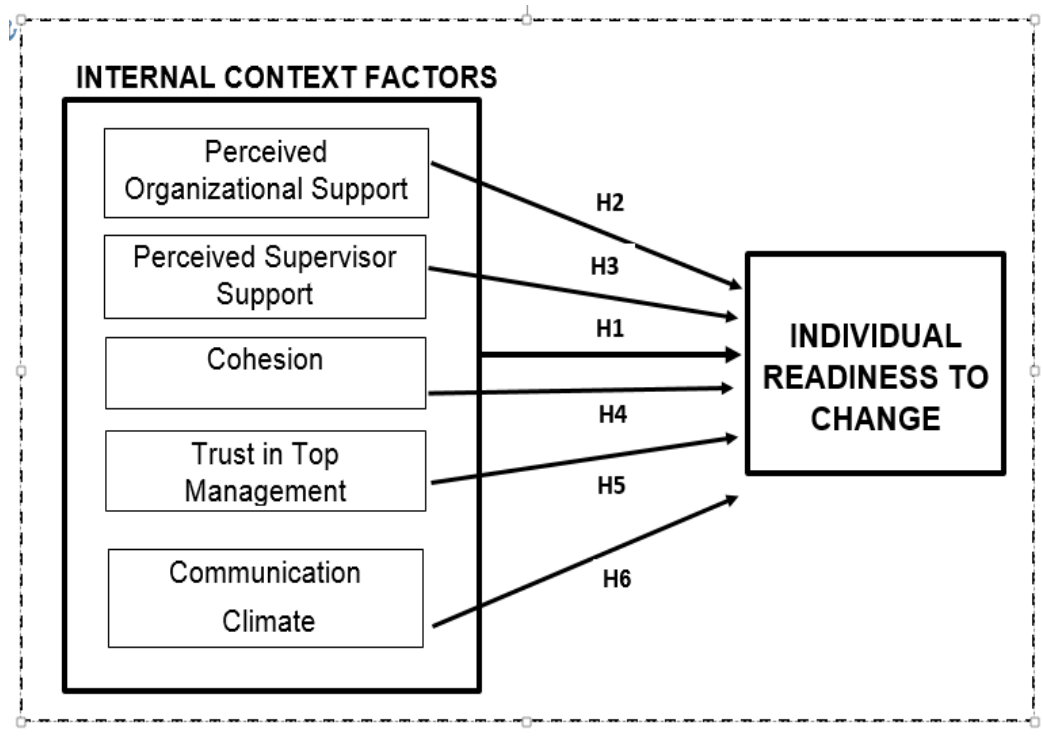

Fig. 1: Theoretical Framework

\section{Hypotheses:}

The following two hypotheses are presented in this study:

H1: There is a significant positive relationship between internal context factors and individual readiness to change (IRTC). 
H2: There is a significant positive relationship between perceived organizational support and individual readiness to change (IRTC).

H3: There is a significant positive relationship between perceived supervisor support and individual readiness to change (IRTC).

H4: There is a significant positive relationship between cohesion and individual readiness to change (IRTC).

H5: There is a significant positive relationship between trust in top management and individual readiness to change (IRTC).

H6: There is a significant positive relationship between communication climate and individual readiness to change (IRTC).

\section{Research Method:}

In order to examine the relationship between internal context factors and individual readiness to change (IRTC) among the non-academic staff at the University of Malaya, a quantitative method was conducted. This study applied the survey method using questionnaire as the instrument. All the instruments used to develop the questionnaire are adopted from the previous researches.

First, individual readiness to change (IRTC): the Scale for IRTC was developed by Vakola (2014) and Holt et al. (2007). The researchers applied the six-item scale from Vakola (2014) to measure the individual readiness to change. Second, perceived organizational support (POS): the instrument used to measure the perceived organizational support (POS) was adopted from Eisenberger, et al . (1986) instrument. The six items were chosen from the list of perceived organizational support (POS) instrument. Third, perceived supervisor support (PSS): this variable was measured through 4-item scale used by Bouckenooghe (2009). Forth, cohesion (COHES): Cohesion was measured through (add) four items based on the scale used by Bouckenooghe (2009). Fifth, trust in top management (TRUST): trust in top management was measured through 4 items based on the scale presented by Mayer and Davis (1999). Sixth, communication climate (COMM): the instrument used for communication climate was adopted from Miller et al. (1994) instrument.

\section{Respondents Profile:}

The target population in this study is the non-academic staff who involved in the third-phase audit of Audit Inspection (Audit Naziran) (staff at the managerial and executive level and also staff at support level (nonexecutive level) at the University of Malaya. The total number of target population involved was approximately 1140 employees. The Krejcie and Morgan (1970) table showed 290 samples are needed. From the 400 questionnaires that were distributed, 330 questionnaires were returned, indicates a response rate of 82.5 per cent. The total of usable questionnaires for the research was 312. From the total of 312 respondents, the majority of the respondents were female $73.4 \%$ and $26.6 \%$ were male. $50.6 \%$ of the respondents were between 30 to 39 years old. $72.4 \%$ are in the non-executive level (support staff) and $24.4 \%$ from the Managerial and executive level. The percentage of those who hold degree and graduate degree was $37.1 \%$, followed by those who hold Malaysian Certificate of Education-Sijil Pelajaran Malaysia (SPM) qualification at 34.3\%, and followed by those who hold diploma-STPM qualification at $28.5 \%$ respectively. When the (add) respondents are evaluated on the basis of their current working experience, many of the respondents $31.4 \%$ have 6 to 10 years working experience; $26.6 \%$ had 1 to 5 years working experience, while $35.9 \%$ had (delete) have (add) more than 10 years working experience. Only $6.1 \%$ from the total respondents is among the new employees who have less than one year working experience in the current university.

\section{Data Analysis:}

The descriptive statistics and inferential statistics were used for analyzing the data. The data collected was statistically analyzed by using the Statistical Package for the Social Sciences (SPSS) version 23.

\section{Results:}

\section{Correlation:}

To examine the relationships among the variables, Pearson correlation had been done and the results are shown in Table 1.

Table 1: Correlation

\begin{tabular}{|c|c|c|c|c|c|c|}
\hline & 1 & 2 & 3 & 4 & 5 & 6 \\
\hline 1 Perceived Organizational Support & 1 & & & & & \\
\hline 2 Perceived Supervisor Support & $.411^{* *}$ & 1 & & & & \\
\hline 3 Cohesion & $.291 * *$ & $.298 * *$ & 1 & & & \\
\hline 4 Trust In Top Management & $.308 * *$ & $.156^{* * *}$ & $.182 * *$ & 1 & & \\
\hline 5 Communication Climate & $.287 * *$ & $.189^{* * *}$ & $.206 * *$ & $.183 * *$ & 1 & \\
\hline 6 Individual Readiness to Change & $.240 * *$ & $.380 * *$ & $.115^{*}$ & $.163 * *$ & $.146^{* * *}$ & 1 \\
\hline
\end{tabular}


The table 1 shows the internal context factors correlate positively and significantly with individual readiness to change (IRTC). The previous literature supported there were relationships between those factors and individual readiness to change (IRTC). The results were shown even though the relationships between the variables with individual readiness to change (IRTC) are significant but those are considered weak. Since the correlation coefficients for most of the variables with individual readiness to change (IRTC) are small, less than 0.3, except Perceived Supervisor Support (PSS) with moderate correlation .380.

\section{Reliability:}

In order to ensure the goodness of measures, reliability test was run. In this research the Cronbach's alpha was applied to ensure the reliability of the questionnaire.

The Cronbach's alpha was calculated through applying Statistical Package for Social Science (SPSS) software. According to Saunders et al. (2009), alpha values between 0.65 to 0.95 are considered satisfactory. The results show the questionnaire was reliable (Table 2).

Table 2: Reliability

\begin{tabular}{ll}
\hline Variable & $\begin{array}{l}\text { Cronbach's } \\
\text { Alpha }\end{array}$ \\
\hline Perceived Organizational Support (POS) & .859 \\
\hline Perceived Supervisor Support (PSS) & .830 \\
\hline Cohesion (COHES) & .703 \\
\hline Trust in Top Management (TRUST) & .819 \\
\hline Communication Climate (COMM) & .888 \\
\hline Individual Readiness to Change (IRTC) & .874 \\
\hline
\end{tabular}

Validity:

Pilot test was applied to test the validity of the survey. The questionnaire first translated to Malay language by the bilingual expert in order to ensure the respondents can fully understand all the questions asked. Then it was re-translated to English language to maintain the equivalence of the questionnaire. The pilot study was executed to 25 participants that include staff at the managerial, the executive level and the support staff to ensure the general linguistic clarity for all the items in the questionnaire. The pilot test showed good understanding of all the items.

\section{Normality Test:}

Skewness and Kurtosis value was applied to test the normality of the data. Skewness and Kurtosis for all the variables are shown in Table 3.

Table 3: Results of Normality Test

\begin{tabular}{lll}
\hline Construct & Skewness & Kurtosis \\
\hline Perceived Organizational Support (POS) & -0.064 & -0.153 \\
Perceived Supervisor Support (PSS) & -0.279 & 0.067 \\
Cohesion (COHES) & -0.479 & 0.198 \\
Trust in Top Management (TRUST) & 0.038 & -0.860 \\
Communication Climate (COMM) & -0.419 & 0.477 \\
Individual Readiness to Change (IRTC) & -0.170 & 0.211 \\
\hline
\end{tabular}

The results above show the values for Skewness and Kurtosis are all between -2 to 2, which indicate that the distributions of scores are normal for all the variables in the study.

\section{Descriptive Analysis:}

In order to get the mean and standard deviation of the independent and dependent variables, the descriptive statistics were done through applying Statistical Package for Social Science (SPSS) software. The results are shown in Table 4.

Table 4: Results of Descriptive Analysis

\begin{tabular}{lll}
\hline Construct & Mean & Standard Deviation \\
\hline Perceived Organizational Support (POS) & 16.8077 & 2.80128 \\
Perceived Supervisor Support (PSS) & 18.3814 & 2.81224 \\
Cohesion (COHES) & 17.0994 & 2.71705 \\
Trust in Top Management (TRUST) & 12.9199 & 3.60733 \\
Communication Climate (COMM) & 11.2628 & 1.28615 \\
Individual Readiness to Change (IRTC) & 18.5321 & 2.51534 \\
\hline
\end{tabular}

The results show most of the variables have low mean scores except for Perceived Supervisor Support (PSS) and individual readiness to change (IRTC) that showed higher mean scores than other variables. 


\section{Hypotheses Testing:}

Hypotheses testing divided into two parts. Simple linear regression analysis was done to test the first hypothesis for verifying the direct positive relationship between internal context factors and individual readiness to change (IRTC). Multiple regression analysis was done to test the rest of the hypotheses by analysing the effect of each internal context factor on individual readiness to change (IRTC).

\section{Simple Linear Regression Analysis:}

To verify the direct relationship between internal context factors and individual readiness to change (IRTC), the simple linear regression analysis was applied. To obtain the strength of the relationship between the internal context factors and individual readiness to change (IRTC), the standardized beta coefficient was noticed. The higher score of beta coefficient shows the stronger relationship.

To analyse the first hypothesis, the score for internal context factors was obtained by computing the mean from all the independent variables using Statistical Package for Social Science (SPSS).

A simple linear regression was applied to examine the effect of internal context factors on individual readiness to change (IRTC). The results show significant positive relationship $(\beta=.332, F(1,310)=38.312$, $\mathrm{p}<.001, \mathrm{R}^{2=} .110$ ). The value of $\mathrm{R}^{2}$ indicates the internal context factors account for 11 percent of the variance in individual readiness to change (IRTC). The results obtained from this analysis are shown in Table 5. The results show the hypothesis one is supported.

Table 5: Simple Linear Regression Analysis for the relationship between Internal Context Factors and Individual Readiness to Change (IRTC)

\begin{tabular}{lllllll}
\hline Predictor Variable & Beta & $\mathrm{R}^{2}$ & Adjusted $\mathrm{R}^{2}$ & $\mathrm{~F}$ & Constant & $\mathrm{t}$-value \\
\hline Internal Context Factors & $.332^{* * *}$ & .110 & .107 & 38.312 & 11.056 & 6.190 \\
\hline
\end{tabular}

***p $<.001$

\section{Multiple regression analysis:}

To find the effect of each internal context factor on individual readiness to change (IRTC), multiple regression analysis was applied. First, to ensure the assumptions of normality, linearity, homoscedasticity and multicollinearity were not violated, the preliminary analysis was done. To check the normality assumption, the Normal Probability Plot (P-P) of the Regression Standardized Residual was noticed. Almost all the points lied on a reasonable straight line which indicates the data set was normally distributed. As multiple regression analysis is sensitive to the outliers, the Scatter Plots figure was noticed. There were no cases having standardised residual larger than 3.3 (absolute value) which indicates there is no problem with outliers (Tabachnick and Fidell, 2013). Second, to find out our data set violated the homoscedasticity assumption, the Scatter plots of the standardised residuals was noticed. The residuals seemed to be symmetrically distributed, and randomly scattered towards the centre (along 0 point). The analysis indicates no deviation from centre, therefore no violation of homoscedasticity assumption was observed. Lastly, multicollinearity which would affect the analysis of regression was concerned. Multicollinearity occurs when the independent variables are highly correlated with each others. Based on the correlation matrix, there was no evidence of high correlation among the independent variables ( $r=.9$ and above). To further check that assumption, the two values in Coefficient table, Tolerance and VIF (Variance Inflation Factor) were noticed. In order to ensure no multicollinearity among the variables in the multiple regression, the rules of thumb must be concerned: Tolerance value above .10 , or a VIF (Variance Inflation Factor) value less than 10. Based on both values in the analyses, there was no multicollinearity, therefore, no violation of the assumption was observed.

To test the hypotheses of the current survey and to examine how much variance in individual readiness to change (IRTC) can be explained by the model (which consists of five variables: POS, PSS, COHES, TRUST, COMM), value of $R$ square was concerned (Table 6).

Table 6: R Square

\begin{tabular}{|c|c|c|c|c|}
\hline Model & $\mathrm{R}$ & R Square & Adjusted R Square & Std. Error of the Estimate \\
\hline 1 & $.404^{\mathrm{a}}$ & .163 & .149 & 2.32011 \\
\hline
\end{tabular}

Table 6 indicates $\mathrm{R}$ square value at .163, therefore the model has explained 16.3 percent of the variance in individual readiness to change (IRTC). In order to assess whether the above result reached the statistical significance, The Sig. at table 7 was noticed. The Sig value .000 indicates the model significantly predicts individual readiness to change (IRTC) $\left(\mathrm{F}(5,306)=11.908, \mathrm{p}<.001, \mathrm{R}^{2}=.163\right)$. 
Table 7: ANOVA

\begin{tabular}{lllllll}
\hline Model & & Sum of Squares & df & Mean Square & F & 11.908 \\
\\
\hline & Regression & 320.510 & 5 & 64.102 & & \\
& Residual & 1647.170 & 306 & 5.383 & & \\
& Total & 1967.679 & 311 & & & \\
\hline
\end{tabular}

Dependent Variable: Individual Readiness to Change

a. Predictors: (Constant), Communication Climate, Trust In Top Management, Perceived Supervisor Support, Cohesion,

Perceived Organizational Support

To find whether each of the variables includes in the model has significant effect on individual readiness to change (IRTC), multiple regression analysis was concerned. To compare the contribution of each internal context factor, the beta values were noticed at table 8 .

Table 8: Results of Multiple Regressions Coefficients ${ }^{\mathrm{a}}$

\begin{tabular}{|c|c|c|c|c|c|}
\hline & $\begin{array}{l}\text { Unstandardized } \\
\text { Coefficient }\end{array}$ & & $\begin{array}{l}\text { Standardized } \\
\text { Coefficient }\end{array}$ & & \\
\hline & B & Std. Error & $\operatorname{Beta}(\beta)$ & $\mathrm{t}$ & Sig \\
\hline $\begin{array}{ll}\text { Perceived } & \text { Organizational } \\
\text { Support (POS) } & \\
\end{array}$ & .063 & .055 & .070 & 1.135 & .257 \\
\hline $\begin{array}{lll}\begin{array}{l}\text { Perceived } \\
\text { (PSS) }\end{array} & \text { Supervisor } & \text { Support } \\
\end{array}$ & .302 & .053 & .337 & 5.748 & .000 \\
\hline Cohesion (COHES) & -.030 & .052 & -.032 & -.575 & .566 \\
\hline $\begin{array}{l}\begin{array}{l}\text { Trust in Top Management } \\
\text { (TRUST) }\end{array} \\
\end{array}$ & .059 & .039 & .085 & 1.524 & .128 \\
\hline $\begin{array}{l}\text { Communication } \\
\text { (COMM) }\end{array}$ & .105 & .108 & .054 & .972 & .332 \\
\hline
\end{tabular}

a. Dependent Variable: Individual Readiness to Change

Only perceived supervisor support shows significant result with $\beta=.337$, p value $=.000<.05$. The other variables cannot predict individual readiness to change (IRTC) significantly; perceived organizational support $(\beta=.070, p=.257)$; cohesion $(\beta=-.032, p=.566)$; trust in top management $(\beta=.085, p=.128)$; and communication climate $(\beta=.054, \mathrm{p}=.332)$. The multiple regression results reveal that perceived supervisor support (PSS) is the best predictor for individual readiness to change (IRTC).

\section{RESULTS AND DISCUSSION}

One of the objectives of this study is to verify the effect of internal context factors on individual readiness to change IRTC. The result of simple linear regression indicated that internal context factors (measured as a single dimension) significantly and positively affect on individual readiness to change (IRTC). This indicates positive conditions and supportive environment help to increase the level of the individual readiness to change (IRTC). This finding is consistent with what have been suggested recent studies which mention internal context factors or climate of change is one of the dimensions for assessing the individual readiness to change (IRTC) (Holt et al., 2007; Bouckenooghe, 2009). Cullen et al. (2014) suggest that perceptions about the support received from the internal context help the organization to manage uncertainty and anxiety during organizational change. Based on this finding, university leaders can utilize the internal context factors as a strategy to provide the university staff, the necessary support to face change. While the funding reduction may prevent the implementation of the right means to increase the readiness to change among employees, managing internal context factors is one of the moneyless solutions that can help the university leaders to influence the employees' perception on the forthcoming changes.

Other objective of this study is to investigate the effect of each individual internal context factor on individual readiness to change (IRTC). The findings are as follows:

The effect of perceived organizational support on individual readiness to change (IRTC):

The results indicate hypothesis two is not supported. Perceived organizational support (POS) has a very small positive effect on individual readiness to change (IRTC) and the effect is not significant. The findings imply that individual readiness to change (IRTC) among the non-academic staff at the University of Malaya do not relate with their perceptions about organizational support.

\section{The effect of perceived supervisor support on individual readiness to change (IRTC):}

The results indicate hypothesis three is supported. The relationship between the independent variable, perceived supervisor support and the dependent variable, individual readiness to change is positive significant and highlights the importance of perceived supervisor support in creating individual readiness to change (IRTC) among the non-academic staff at the University of Malaya. Perceiving supervisors as supportive, understanding 
and helpful leads to high levels of readiness to change among the non-academic staff. Supervisors can also influence the higher management to provide the employees the necessary resources during change. Deal and Celotti (1980) suggest that supervisors' behaviour is important for job satisfaction, improvement and innovation in the organization. The Study of Chang (1999) indicates that the supervisor's support leads to the employees' positive attitude and behaviours. The study of Madsen et al. (2005) mentions that the supervisor's support creates positive feelings towards workplace among the employees which may generate supportive environment that increases the individual readiness to change (IRTC).

\section{The effect of cohesion on individual readiness to change (IRTC):}

The results indicate hypothesis four is not supported. Cohesion is found to have insignificant and negative effect on individual readiness to change (IRTC). Support by the team members do not impact on increasing the state of readiness among the individuals in the group at the University of Malaya. This finding contradicts with the study of Warnberg and Banas (2000) which indicates the employees' distribution of information, support and their participations lead to the higher level of openness to change.

\section{The effect of trust in top management on individual readiness to change (IRTC):}

The results indicate hypothesis five is not supported. The relationship between trust in top management and individual readiness to change (IRTC) is positive but weak and insignificant.

\section{The effect of communication climate on individual readiness to change (IRTC):}

The results indicate hypothesis six is not supported. The relationship between communication climate and individual readiness to change (IRTC) is positive but weak and insignificant.

The findings of this study indicate the best predictor for the individual readiness to change (IRTC) is perceived supervisor support (PSS). The current result is not surprising because supervisors are close to their subordinates due to their daily routine contact. The study of Eisenberger et al. (2002) mentions the same result also in which the effect of perceived supervisor support (PSS) on individual readiness to change (IRTC) is more than the effect of perceived organizational support (POS). Support by the supervisors can help to reduce stress and increase the employees' ability to cope (Smollan, 2016). Employees who receive favourable treatment from supervisors normally feel obliged to show readiness to any form of organizational change.

\section{Contributions:}

Change is constant, public universities in Malaysia due to the rapid change in the external environment as well as global competition in higher education, encounter organizational change. The survival of today's Public Institutions of Higher Education (PIHE) relies on how these organizations accept changes, improve practices and expand competitiveness (Ghaffari et al, 2017). The main role of individuals in organizational change success cannot be neglected. Therefore, it is important for public universities to understand what factors influence the willingness of individual employees to accept change. The current study has discussed some of the factors and specifically some of the internal factors which have influence on the individual readiness to change. The empirical evidences of the current study have shown that perceived supervisor support was one of the factors that contribute to the individual readiness to change. Therefore the leaders of the public universities should pay more attention on their supervisory role in enhancing the level of readiness to change among the University employees.

Few studies have been done to study the link between perceived supervisor support and individual readiness to change. The studies that have been done in the area of change management have not examined the relation of these two variables explicitly. Therefore the significant empirical evidences of the current research contribute to fill the gap in the change management literature with the focus on the study of the relationship between the perceived supervisor support and the individual readiness to change.

\section{Limitation of the study:}

Due to the time limitation and the scope of the current study, the researchers only focused on the internal context factors, specifically some of the internal factors. The related literature proved there are many dimensions that influence the individual readiness to change. The dimension of internal context factors consists other variables also which are examined by previous researchers. Therefore, to get the whole picture about the level of readiness to change among the University employees, there are other variables that need to be explored, which because of the time constrain in this research, couldn't be investigated. This research was done only in the specific time and focused on the certain groups of employees who were the non-academic staff in the managerial and the professional levels and the staff at the support level which for sure had influence on the findings of this study. 


\section{Conclusion:}

To know what factors may affect the individual readiness to change among the employees is important for the organizations. The findings of this study indicate the best predictor for the individual readiness to change (IRTC) is perceived supervisor support. The result of the current research is helpful for the leaders of the University of Malaya, since proved the significant effect of their supervisory role in increasing the level of individual readiness to change among the University employees. Since the current research only focused on the internal context factors and only some of these inertial variables were selected to study, there are other factors that may affect the individual readiness to change among the University employees which can be concerned by the future researchers.

\section{REFERENCES}

Abd Rahman, A. and F. Alan, 2013. Funding Reforms in Malaysian Public Universities from the Perspective of Strategic Planning. Malaysia: Procedia-Social and Behavioural Sciences, 129: 105-110.

Armenakis, A.A., S.G. Harris and K.W. Mossholder, 1993. "Creating Readiness for Organizational Change," Human Relations, 46(6): 681-702.

Bouckenooghe, D., 2008. What Is Crucial in Developing a Positive Attitude Toward Change? The Role of Content, Context, Process and Individual Variables to Understanding Readiness for Change, Doctoral Dissertation, Ghent University.

Bouckenooghe, D., G. Devos and H.V.D . Broeck, 2009. Organizational Climate Questionnaire- Climate of Change, Processes, and Readiness: Development of a New Instrument, The Journal of Psychology, 143(6): 559599.

Chang, E., 1999. Career Commitment as a Complex Moderator of Organizational Commitment and Turnover Intention, Human Relations, 52(10): 1257-78.

Daft, R.L., 1982. Bureaucratic vs. Non-bureaucratic Structure in the Process of Innovation and Change, In S.B. Bacharach (Ed.) Perspectives in Organizational Sociology: Theory and Research, Greenwich, CT: JAI Press.

Dalton, C.C and L.N. Gottlieb, 2003. The Concept of Readiness to Change, Journal of Advanced Nursing, 42(2): 108-17.

Deal, J.E. and L.D. Celloti, 1980. How Much Influence Do and Can Educational Administrators Have on Class Rooms? Phi Delta Kappan, 61(7): 471-3.

Eisenberger, R., R. Huntington, S. Hutchison and D. Sowa, 1986. Perceived Organizational Support, Journal of Applied Psychology, 71(3): 500-507.

Eisenberger, R. and L. Rhoades, 2002. Perceived Organizational Support: A Review of Literature, Journal of Applied Psychology, 87(4): 698-714.

Fariza, H.R., L.C. James and S. Peter, 2011. Positioning Change Readiness in Knowledge Management Research, Journal of Knowledge Management, 16(2): 329-355.

Fiorelli, J.S. and H. Margolis, 1993. Managing and Understanding Large Systems Change: Guidelines for Executives and Change Agents, Organization Development Journal, 11(3): 1-13.

Ghaffari, S., J. Burgoyne, S. Ishak and M. Nazri, 2017. Perceptions of Learning Organization Dimensions among the Non-academic Employees of Top Public Universities in Malaysia, Australian Journal of Basic and Applied Sciences, 11(1): 107-116.

George, J.M. and G.R. Jones, 2001. Towards a Process Model of Individual Change in Organizations, Human Relations, 54: 419-444.

Holt, D.T., 2002. Readiness for Change: The Development of a Scale, Doctoral Dissertation, Auburn University, Alabama.

Holt, D.T., A.A. Armenakis, H.S. Field and S.G. Harris, 2007. Readiness for Organizational Change: The Systematic Development of a Scale, The Journal of Applied Behavioural Science., 43(2): 232-255.

Judge, T., C. Thoresen, V. Pucik and T.W elbourne, 1999, Managerial Coping with Organizational Change: a Dispositional Perspective, Journal of Applied Psychology, 84(2): 107-122.

Kottke, J.L. and C.E. Sharafinski, 1988. Measuring Perceived Supervisory and Organizational Support, Educational and Psychological Measurement, 48: 1075-1079.

Krejcie, R. and D. Morgan, 1970. Determining Sample Size for Research Activities, Educational and Psychological Measurement, 30: 607-610.

Madsen, S.R., D. Miller and C.R. John, 2005. Readiness for Organizational Change: Do Organizational Commitment and Social Relationships in the Workplace Make a Difference?" Human Resource Development Quarterly, 16(2): 213-33.

Mayer, R.C., J.H. Davis and D. Schoorman, 1995. An Integrative Model of Organizational Trust, Academy of Management Review, 20(3): 709-734. 
Mayer, R.C. and J.H. Davis, 1999, The Effect of Performance Appraisal System on Trust for Management," Journal of Applied Psychology, 84: 123-136.

Miles, M.B., A.M. Huberman and J. Saldana, 2014. Qualitative Data Analysis: A Methods Sourcebook, 3rd ed., Thousand Oaks, CA: Sage.

MOHE., 2007a. National Higher Education Action Plan 2007-2010, In M.o.H. Education (Ed.). Putrajaya.

MOHE., 2007b. Pelan Strategik Pengajian Tinggi Negara Melangkau Tahun 2020. Putrajaya.

Miller, V.D., J.R. Johnson and J. Grau, 1994. Antecedents to Willingness to Participate in a Planned Organizational Change, Journal of Applied Communication Research, 22: 365-386.

Naimatullah Shah, 2010. Relationships between Employee Readiness for Organizational Change, Supervisor and Peer Relations and Demography, Journal of Enterprise Information Management, 23(5): 640652 .

Saunders, M., P. Lewis and A. Thornhill, 2009. Research Model for Business Studies, 5ed, Financial Times Prentice Harlow.

Smollan, R., 2016. Stressful Organizational Change: The role of Support in Coping, Italy: European Group for Organizational Studies (EGOS).

Soaib, A. and H. Sufean, 2012. University Governance: Trends and Models, Kuala Lumpur, Malaysia: University of Malaya Press.

Synder, R.A. and J.H. Morris, 1984. Organizational Communication and Performance, Journal of Applied Psychology, 69: 461-465.

Tabachnick, B.G. and L.S. Fidell, 2013. Using Multicariate Statistics, $6^{\text {th }}$ edn, Boston: Pearson Education.

Thompson, R. C. and J.G. Hunt, 1996. Inside the Black Box of Alpha, Beta, and Gamma Change: Using a Cognitive-processing Model to Assess Attitude Structure, Academy of Management Review, 21: 665-690.

Vakola, M., 2014. What's in There for Me? Individual Readiness to Change and the Perceived Impact of the Organizational Change, Leadership \& Organization Development Journal, 35(3): 195-209.

Walinga, J., 2008. Toward a Theory of Change Readiness: The Roles of Appraisal, Focus, and Perceived Control, The Journal of Applied Behavioural Science., 44(3): 315-347.

Warnberg, C.R. and J.T. Banas, 2000. Predictors and Outcomes of Openness to Changes in a Reorganizing Workplace, Journal of Applied Psychology, 35(1): 132-145. 